\title{
A SECOND EXPERIMENT WITH HETEROSPERMIC INSEMINATION IN CATTLE
}

\author{
D. L. STEWART,* R. L. SPOONER, $\dagger$ G. H. BENNETT,* \\ R. A. BEATTY $\ddagger$ AND J. L. HANCOGK $\$$ \\ * Ministry of Agriculture, Fisheries and Food, Cattle Breeding Centre, Shinfield, \\ Reading, †Agricultural Research Council Cattle Blood-Typing Service, \\ Animal Breeding Research Organization, King's Buildings, West Mains Road, \\ Edinburgh 9, $¥$ Agricultural Research Council Unit of Animal Genetics, \\ Department of Genetics, King's Buildings, West Mains Road, Edinburgh 9, \\ $\$$ Department of Anatomy, Royal Veterinary College, Royal College Street, \\ London, $\mathcal{N} . W .1$
}

(Received 16th January 1973)

\begin{abstract}
Summary. Spermatozoa from four Friesian bulls were mixed in equal numbers. After insemination of the mixture, the paternity of calves was scored by blood-typing. Consistent results were obtained over replicate experiments conducted in each of 6 successive weeks. After insemination of 'fresh' mixed semen, the number of calves sired per bull were in a ratio close to $1: 1: 1: 1$. Normal conception rate tests with fresh semen from one bull at a time (4- and 16-week non-return rates) also showed no significant differences in bull fertility. After inseminating mixtures subjected to deep-freezing at $-196^{\circ} \mathrm{C}$, the numbers of offspring were no longer nearly equal; one bull now sired $\sim 50 \%$ of the progeny. It is concluded that bulls vary in the ability of their spermatozoa to withstand deep-freezing. No significant prediction of semen fertility based on staining affinity of spermatozoa could be realized, but the experiment was of limited size for this particular purpose. In two sets of twins, the co-twins were sired by different fathers. The sex ratio of progeny was unaffected. Experiments of this type offer no apparent risk to cooperating farmers, since overall conception rate was not diminished. Stocks of deep-frozen semen have been laid down for testing in subsequent years.
\end{abstract}

\section{INTRODUCTION}

Heterospermic insemination with mixed semen from more than one sire is an alternative to homospermic ('ordinary') insemination with semen from one sire only. The paternity of offspring after heterospermic insemination can be scored by means of prearranged genetic markers. In an experiment with ten bulls (Beatty, Bennett, Hall, Hancock \& Stewart, 1969), equal numbers of spermatozoa from two sires at a time were inseminated. We shall refer to this as the 'previous experiment'. Paternity was scored in that experiment by using coat 
and conformation characteristics of different breeds, and for this reason sperm mixtures could be made only between bulls of different breed. In the present experiment, each mixed inseminate contained equal numbers of spermatozoa from four bulls of the same breed (Friesian), paternity being scored by bloodtyping. Information about several questions was desired. Can such experiments be carried out without undue difficulty within the normal operational framework of an A.I. Centre? Does the relative fertility of semen from individual bulls change after deep-freezing the mixed semen? Are there fertility differences between bulls of the same breed?

\section{MATERIALS AND METHODS}

The experiment was replicated over 6 successive weeks during December 1969 and January 1970. In each week, ejaculates were collected from the four bulls over a 45 -min period, the order of collection being randomized between weeks. The sperm concentration was determined in each ejaculate by the photometric method of Cox \& Melrose (1953), and nigrosin-eosin smears were made by the method of Hancock (1957). In each week, an aliquot of each of the four ejaculates containing $800 \times 10^{6}$ spermatozoa was added to separate $10-\mathrm{ml}$ vols of milk/yolk diluent. Four other aliquots containing $2500 \times 10^{6}$ spermatozoa were added to $20-\mathrm{ml}$ vols of yolk/citrate diluent. The eight sets of diluted semen were transferred to a water-bath at $15^{\circ} \mathrm{C}$ and then placed in a refrigerator at $5^{\circ} \mathrm{C}$ for $15 \mathrm{~min}$.

For the 'fresh semen' series, the diluted semen from the four males in milk/ yolk diluent was mixed thoroughly and made up to a final volume of $80 \mathrm{ml}$ with milk/yolk diluent. It was placed in ampoules and distributed for insemination the following day, each inseminate containing $10 \times 10^{6}$ spermatozoa from each of the bulls, in a total volume of $1 \mathrm{ml}$.

For the 'frozen semen' series, the diluted semen from the four bulls in yolk/ citrate diluent was mixed thoroughly and made up to a final volume of $125 \mathrm{ml}$ with the diluent. To this was added $125 \mathrm{ml}$ of $15 \%$ glycerol in $3.6 \%$ aqueous sodium citrate at $5^{\circ} \mathrm{C}$, the mixture was equilibrated for $18 \mathrm{hr}$, distributed into ampoules the following morning, then frozen and stored in liquid nitrogen, and inseminated 1 to 2 days later. Each inseminate contained $10 \times 10^{6}$ spermatozoa from each bull, in a total volume of $1 \mathrm{ml}$.

An initial 'trial run', not recorded here, was carried out in order to accustom the numerous operators to the mechanics of the experiment.

Data for the homospermic conception rate for the same bulls after insemination of fresh semen (4-week and 16-week non-returns) were obtained during January to March 1969, i.e. in the period immediately following the heterospermic experiment.

To facilitate the identification of sires, the four bulls had been chosen after preliminary work so that they had different blood-group patterns:

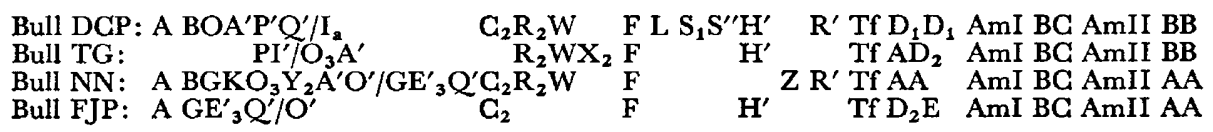


Blood samples from sires, dams and progeny were collected in acid citrate dextrose and tested in the routine cattle blood-typing service at Edinburgh. Briefly, the method involved a haemolytic test using rabbit complement and bovine antisera, carried out at room temperature in microtitre plates. Thirty-six red cell reagents detecting antigens at nine loci were used. In addition, polymorphism in several serum and red cell proteins was studied by means of starch-gel electrophoresis. Tris cacodylic acid buffer, $\mathrm{pH}$ 7.25 (Spooner \& Baxter, 1969) was used in testing transferrins, and tris citric acid buffer, $\mathrm{pH} 7 \cdot 0$, when testing two amylase loci (Mazumder \& Spooner, 1970).

The sires of $98 \%$ of the calves could be recognized. In only five cases were all four bulls excluded as possible sires. In some other cases, which initially appeared incorrect, an error in identification was detected and the correct sire was determined on re-sampling. In two cases, the dam proposed was incorrect. Only one calf died before a blood-sample could be obtained.

\section{RESULTS}

Semen quality judged by staining affinity

Nigrosin-eosin preparations were made at all stages of the experiment from each ejaculate used for heterospermic insemination. The sampling structure was: four bulls: 6 weeks: two duplicate suspensions for each of the twenty-four bull/week combinations: two microscope preparations per suspension. Three sperm attributes were scored from 100 spermatozoa per preparation: the $\%$ unstained, the $\%$ part-stained, and the $\%$ fully stained; the sum of the three percentages for each preparation was 100 . All slides of the experiment were scored in a single randomized order, after coding to veil their identity.

The bulls/weeks interaction was statistically significant for all three attributes. It was used as error term for testing differences between bull means and between weekly means in analyses of variance. The general pattern of variation is shown in the upper part of Table 1, the figures being root variance components (standard deviations) that express the variability specifically associated with each source of variation, freed from the effects of the other sources. These figures allow one to see by inspection the relative importance of the different sources of variation. From the significance levels (copied from prior analyses of variance), it is clear that there were marked and highly significant differences between bulls in the percentages of unstained and of fully stained spermatozoa. The components for 'weeks' were small and non-significant, thus indicating good repeatability of results from one week to another, and also indicating the absence of any time trend in the results. The means for the individual males are given in the lower part of Table 1, with standard errors derived from the bulls/weeks interaction. The 'worst' bull was DCP, with a low percentage of unstained and a high percentage of fully stained sperm heads, whereas the other bulls were mutually indistinguishable.

\section{Homospermic non-return rate}

Semen was used the day after collection. The 4-week and 16-week homospermic non-return rates in the months of January, February and March 1969 
are given in Table 2 . There was evidently some erratic fertility (i.e. a bull/month interaction) associated principally with a poor non-return rate by DCP in March. Analyses of variance of the unweighted mean non-return rates in the table showed no significant overall differences between bull means, nor between monthly means, for either the 4-week or the 16-week data. The overall non-return rate was $79 \%$ at 4 weeks and $63 \%$ at 16 weeks.

\section{Heterospermic inseminations}

Effect of deep-freezing on heterospermic performance of bulls (Table 3c). The main result of the experiment can be judged from the eight numbers at the bottom

Table 1. Percentage stained sperm heads in nigrosin-eosin preparations of the semen of four bulls

\begin{tabular}{|c|c|c|c|c|}
\hline \multirow{2}{*}{$\begin{array}{l}\text { Factor } \\
\text { (a) }\end{array}$} & \multirow[b]{2}{*}{ d.f. } & \multicolumn{3}{|c|}{ Root variance components } \\
\hline & & $\%$ unstained & $\%$ part stained & $\%$ fully stained \\
\hline $\begin{array}{l}\text { Bulls, B } \\
\text { Weeks, W } \\
\text { Interaction, BW } \\
\text { Spermatozoa, S(BW) } \\
\text { Preparations, p(S, BW) } \\
\text { Binomial error }\end{array}$ & $\begin{array}{r}3 \\
5 \\
15 \\
24 \\
48 \\
\infty\end{array}$ & $\begin{array}{l}11 * * * * \\
4 \\
9 * * * * \\
3 * * \\
2 \\
5^{\mathrm{NT}}\end{array}$ & $\begin{array}{l}2^{(*)} \\
1 \\
3^{*} \\
0 \\
4^{* * * * *} \\
3^{\text {NT }}\end{array}$ & $\begin{array}{l}9^{* * * * *} \\
3 \\
8^{* * * * *} \\
4^{* *} \\
3^{* * * *} \\
4^{\mathrm{NT}}\end{array}$ \\
\hline \multirow{2}{*}{$\begin{array}{l}\text { (b) } \\
\text { Male }\end{array}$} & & \multicolumn{3}{|c|}{ Mean counts per male } \\
\hline & & $\%$ unstained & $\%$ part stained & $\%$ fully stained \\
\hline $\begin{array}{l}\text { DCP } \\
\text { TG } \\
\text { NN } \\
\text { FJP }\end{array}$ & & $\begin{array}{l}49 \\
75 \\
72 \\
70\end{array}$ & $\begin{array}{r}13 \\
6 \\
10 \\
12\end{array}$ & $\begin{array}{l}38 \\
18 \\
18 \\
18\end{array}$ \\
\hline $\begin{array}{l}\text { S.E. per mean } \\
\text { Sign. of o differences }\end{array}$ & & $\underset{* * * *}{ \pm 3 \cdot 9}$ & $\underset{(*)}{ \pm 1 \cdot 6}$ & $\frac{ \pm 3 \cdot 6}{* * * *}$ \\
\hline
\end{tabular}

Key to significance levels: NT, no test; $\left(^{*}\right) P \sim 0.05 ; * 0.05>P>0.025$; $* * 0.025>P>0.01 ; * * * * 0.005>P$.

(a) Root variance components (standard deviations) showing the relative importance of each factor. The components and significance levels are derived from standard analyses of variance, $B$ and $W$ being tested to $B W$, and the remaining factors each tested to the next lowest factor.

(b) Mean counts per male, with S.E. derived from the BW interaction.

of Table 3. The numbers of offspring $(28: 26: 30: 40)$ sired by the four bulls (DCP:TG:NN:FJP) after using fresh semen do not differ significantly from an assumed $1: 1: 1: 1$ ratio $\left(\chi_{[3]}^{2}=3.74: P=0.3\right.$ to $\left.0 \cdot 2\right)$. But the numbers after frozen semen $(50: 13: 12: 36$ differ from the $1: 1: 1: 1$ ratio with a very high degree of significance $\left(\chi^{2}{ }_{[3]}=37 \cdot 1: P \ll 0 \cdot 001\right)$. Further, the two sets of progeny numbers differ from one another with a high degree of significance $\left(\chi_{[3]}^{2}=17.8: P<0.001\right)$.

The difference in heterospermic performance between the fresh and frozen series is due principally to a change in the relative performance of bull DCP versus the other three bulls. It sired $23 \%$ of the progeny in the 'fresh' series, but $45 \%$ in the 'frozen' series. This conclusion was supported by tests on two 
bulls at a time. Six $2 \times 2$ tables can be made up from the last row of Table 3 , exemplified by the data for DCP:TG(28:26 with 'fresh' semen, 50:13 with 'frozen' semen). The $\chi^{2}$ tests on 1 d.f. showed significant heterogeneity whenever DCP was one partner in a $2 \times 2$ table, and either non-significance (or, in one test, a low degree of significance) whenever DCP was not a partner. Further, there is no significant heterogeneity between the 'fresh' and 'frozen' series for bulls TG, NN, and FJP alone $\left(\chi^{2}{ }_{[2]}=4.69: P=0.1\right.$ to 0.05$)$.

Uniformity of heterospermic performance in different weeks (Table $3 \mathrm{~b}$ ). The validity of the preceding tests depends on the assumption that heterospermic performance was uniform over the 6 different weeks of the experiment. There is good evidence of uniformity. The $\chi^{2}$ tests on 15 d.f. applied to each of the $4 \times 6$ arrays in Table $3(\mathrm{~b})$, and also applied to a third array obtained by pooling

Table 2. Homospermic fertility: 4- and 16-week percentage non-return rates for four bulls

\begin{tabular}{|c|c|c|c|c|c|}
\hline 4-week non-return $(\%)$ & Fanuary & February & March & Mean & S.E./bull mean \\
\hline $\begin{array}{l}\text { DCP } \\
\text { TG } \\
\text { NN } \\
\text { FJP }\end{array}$ & $\begin{array}{l}82(228) \\
86(132) \\
79(226) \\
82(101)\end{array}$ & $\begin{array}{l}82(387) \\
79(429) \\
76(208) \\
79(280)\end{array}$ & $\begin{array}{l}60(108) \\
80(207) \\
79(513) \\
83(548)\end{array}$ & $\begin{array}{l}75 \\
82 \\
78 \\
81\end{array}$ & $\pm 3 \cdot 87_{[6]}$ \\
\hline Mean & 82 & 79 & 76 & 79 & \\
\hline $\begin{array}{l}\text { 16-week non-return }(\%) \\
\text { DCP } \\
\text { TG } \\
\text { NN } \\
\text { FJP }\end{array}$ & $\begin{array}{l}64(228) \\
68(132) \\
65(226) \\
72(101)\end{array}$ & $\begin{array}{l}63(387) \\
66(429) \\
62(208) \\
62(280)\end{array}$ & $\begin{array}{l}44(108) \\
62(207) \\
62(513) \\
68(548)\end{array}$ & $\begin{array}{l}57 \\
66 \\
63 \\
67\end{array}$ & $\pm 3 \cdot 23_{[6]}$ \\
\hline Mean & 68 & 63 & 59 & 63 & \\
\hline
\end{tabular}

The figures in parentheses are the numbers of inseminations. The standard errors are derived from the bulls/months interaction, using the unweighted means.

data for fresh and frozen semen, all indicated statistical homogeneity, with $P$ values in the range 0.8 to $0 \cdot 3$. However, the structure of the experiment is essentially factorial, the sources of variation potentially affecting the relative heterospermic performance of bulls being treatments (i. e. fresh versus frozen): weeks: and treatments/weeks interaction. A factorial heterogeneity $\chi^{2}$ analysis cannot readily be carried out unless the total number of offspring is the same in each week and in each treatment. The lowest such number is 13 (Week 1 , frozen semen). To equalize numbers, individual data were cast out from each treatment/week combination by a formal randomization procedure, so that the totals in each of the combinations became 13. A factorial heterogeneity $\chi^{2}$ analysis of the now numerically balanced, though reduced, data showed that the factors for weeks and for treatments/weeks interaction were each nonsignificant, with $P$ values in the range 0.7 to $0 \cdot 3$. We therefore assume with some confidence that heterospermic performance was uniform from one week to another, deviations from uniformity being no more than would be expected from sampling error. 


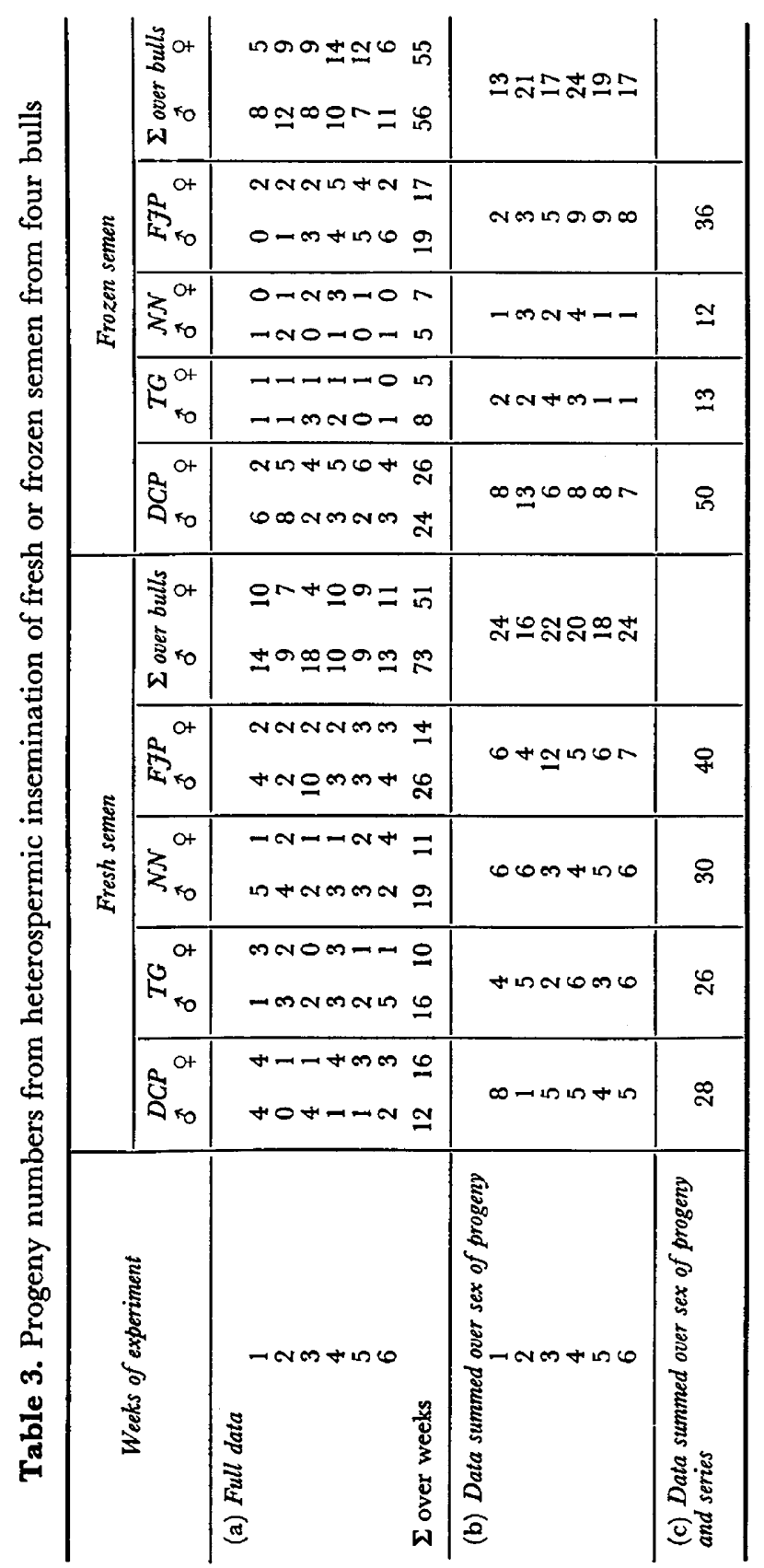


Sex ratio among progeny (Table $3 \mathrm{a}$ ). In the data for fresh semen in Table $3 \mathrm{a}$, $\chi^{2}$ tests applied to the ' $\Sigma$ over bulls' column and to the ' $\Sigma$ over weeks' row revealed no significant heterogeneity in sex ratios. The same homogeneity was encountered when the data for frozen semen were tested, and when pooled data for fresh and frozen semen were tested. All $P$ values were in the range $0 \cdot 8$ to $0 \cdot 2$. The overall sex ratios for fresh semen $\left(73 \delta^{*}: 51\right.$ ) $)$ and for frozen semen $\left(560^{*}: 55\right.$ o $)$ do not differ significantly $\left(\chi_{[1]}^{2}=1 \cdot 67: P=0 \cdot 2\right.$ to $\left.0 \cdot 1\right)$. We are therefore justified in pooling data over the whole experiment, the figure being 1298:106o, or $54.9 \%$ male \pm 3.25 S.E., which does not differ significantly from the Mendelian expectation of $50 \%$ male offspring.

Segregation of blood-group alleles. The segregation ratios for B alleles for the offspring of TG were significantly different from the expected 50:50 ratio at the $0.05 P$ level but were in agreement with expectation in the other three bulls. In all bulls, Mendelian expectation was obeyed at all other loci.

Twins. There were seven pairs of twins, all non-identical. Each twin calf had been treated as statistically independent of the other in the analyses above. In two of these twin pairs, the co-twins had been fathered by different sires; the evidence for this rested on transferrins, where chimaerism does not take place.

\section{DISCUSSION}

\section{Practicability of heterospermic experiments}

It is now becoming apparent that such experiments involve little risk. In the previous experiment (Beatty et al., 1969), the heterospermic 16-week nonreturn rate was $68 \cdot 1 \%$, the homospermic rate being $65.5 \%$, and the heterospermic calving rate was at the adequate level of $53.7 \%$. In the present work, the heterospermic non-return rate was $86.4 \%$ at 4 weeks and $71.9 \%$ at 16 weeks, the homospermic rates being $79 \%$ at 4 weeks and $63 \%$ at 16 weeks; once again, the heterospermic calving rate was at the satisfactory level of $66.0 \%$. Macmillan $\&$ Watson (1971) showed that the 49-day non-return rate after inseminating mixed first and second ejaculates from the same bull was slightly, though nonsignificantly, improved. These figures even suggest that heterospermic insemination as such improves fertility, though we cannot make a positive assertion at this stage. Improved fertility would be expected on the grounds that eggs would automatically tend to be fertilized by the more fertile semen component in a mixture. Untoward effects on the sex ratio of progeny were neither expected nor found in this and the previous experiment.

We have used blood-typing for scoring the paternity of calves because of its special advantages for experimental work. It is efficient, it detects certain errors which can sometimes be rectified by re-sampling, and it permitted comparison of bulls of the same breed. The parentage error rate was found to be lower than in normal pedigree material handled by the blood-typing service, probably because farmers gave special attention to the experimental calves. Further, calves had been ear-marked at an earlier age than is usual, and this undoubtedly helped to minimize errors. Typing would scarcely be possible without a routine blood-typing service but even then, the collection of samples and subsequent 
typing are fairly laborious processes involving considerable expense in the time of technicians and assistants. In any practical applications that might develop from the present work, one would hope to revert to the simpler but less accurate method of scoring paternity by means of the colour and conformation characteristics of breeds, though it would clearly be impracticable to mark in this way within a breed.

\section{Repeatability of heterospermic results}

All the available evidence indicates a most satisfactory degree of repeatability of results. In the present work, the relative heterospermic performance of the four bulls remained constant over the 6 weeks of the experiment. In the previous experiment, the relative heterospermic performance of ten bulls was the same in two series a month apart. Consistent results have also been obtained in the rabbit (Beatty, 1960) and in the mouse (Edwards, 1955). We conclude that the relative heterospermic performance of sires over a period of time is virtually a fixed characteristic of those sires.

\section{Does heterospermic performance predict the homospermic fertility of bulls?}

In the previous experiment, marked differences in the heterospermic performance of ten bulls were correlated positively and significantly with homospermic fertility (16-week non-return rate). The heterospermic method appeared to constitute a particularly efficient way of predicting 'ordinary' homospermic non-return rate. In the present experiment, prediction is also correct, though in a negative sense: if we confine the comparison to inseminations conducted with fresh semen, then there were no significant differences between bulls in either homospermic or heterospermic performance, and no significant correlation between the two measures of fertility. Presumably, in our small sample of four bulls, we happen to have selected bulls that do not differ in fertility after insemination of fresh semen. An additional factor that might tend to cause uniformity in fertility is that the four bulls were of one breed, whereas two breeds were represented in the previous experiment.

\section{Does deep-freezing change the relative heterospermic fertility of bulls?}

The evidence of the experiment is unequivocal: the relative heterospermic performance of bulls changed after deep-freezing at $-196^{\circ} \mathrm{C}$ and maintenance at that temperature for 2 to 3 days. The main change was in the relative fertility of bull DCP versus the other three bulls collectively (or in the other three bulls, collectively, relative to DCP). Bull DCP had sired nearly $25 \%$ of the offspring after insemination of fresh mixed semen, but nearly $50 \%$ of the offspring after deep-freezing of the mixed semen. Evidently, the ability of semen to withstand deep-freezing varies between bulls. This may have practical implications. The biological basis remains unknown. Perhaps, in a general sense, the physiology of spermatozoa from certain bulls is unduly affected by the deep-freezing process, or there may be a specific effect on capacitation time (Dziuk, 1965). We can be fairly sure that the effect is concerned with spermatozoa and is not mediated by embryonic or fetal mortality, because the overall calving rates in both this and the previous experiment were not sub-normal. We may also 
note, as in the previous experiment, that the semen of different bulls in mixed inseminates does not compete on an all-or-none basis since, on two occasions, the co-twins of a twin pair were sired by different fathers.

\section{Prediction of bull fertility from staining affinity in nigrosin-eosin smears}

It seemed, at first sight, disappointing that DCP was the 'worst' bull as judged by staining affinity, but did not differ in fertility from the other bulls after homospermic or heterospermic insemination with fresh semen, and was the 'best' bull after heterospermic insemination with deep-frozen semen. Predictions of fertility from staining affinity, however, 'explain' only some $20 \%$ of the fertility (Bishop, Campbell, Hancock \& Walton, 1954), and there is plenty of scope in the remaining $80 \%$ 'unexplained' variability for our small sample of only four bulls to have included, by accident, bulls that do not happen to reflect the predictive value of measures of staining affinity. Further, we cannot assume a priori that predictions from fresh semen apply to frozen semen.

\section{Heterospermic insemination in other contexts}

We are concerned primarily with sire differences in semen fertility. The technique of heterospermic insemination is also being used for the study of other effects on spermatozoa. Macmillan \& Watson (1971) investigated the fertility of mixed ejaculates from the same bull, and the effect of the time interval between insemination and ovulation has been studied in gilts and ewes by Dziuk (1970) and in the rabbit by Miller, Roche \& Dziuk (1969). In rabbits, there are investigations of capacitation time (Dziuk, 1965), of X-irradiation of spermatozoa (Bedford \& Hunter, 1968), of sperm age and fertility (Roche, Dziuk \& Lodge, 1968), and of competition of 'marked' rabbit spermatozoa in the female tract up to fertilization (O'Reilly, Graves \& Dziuk, 1972).

\section{Future work}

The present work indicates that the deep-freezing process, combined with storage for 2 to 3 days, affects the relative heterospermic performance of semen from particular bulls. We have laid down stocks of deep-frozen mixed inseminates in order to test after a period of years whether long-term storage has any additional effect.

The main practical implication of work on heterospermic insemination is that it may provide a particularly efficient method of predicting a datum important at every AI centre: the relative homospermic fertility of bulls. In the previous experiment, the correlation between homospermic and heterospermic performance was positive. It was statistically significant at the modest $P$ level of 0.05 to 0.025 . The correlation was also significant and positive in rabbits (Beatty, 1960). There is need for a large experiment to establish the reality and magnitude of this correlation. The difficulty does not lie in the heterospermic data, which are capable of establishing differences in heterospermic performance with some precision. The difficulty lies with the other element of the correlation, the homospermic data, where the number of test inseminations per bull has to be of the order of thousands in order to overcome the relatively large sampling error. 


\section{AGKNOWLEDGMENTS}

We wish to thank members of the staff of the Cattle Breeding Centre, in particular Mr I. B. Munro, and veterinary officers of the Animal Health Division stationed at Oxford and Reading for assistance and checking identities and obtaining blood samples. We also thank Mr D. S. Ross and the staff of the blood-typing service for the blood group results. The paper is published with secretarial assistance provided by a grant from the Ford Foundation.

\section{REFERENCES}

Beatty, R. A. (1960) Fertility of mixed semen from different rabbits. F. Genet. 55, 325.

Beatty, R. A., Bennett, G. H., Hall, J. G., Hancock, J. L. \& Stewart, D. L. (1969) An experiment with heterospermic insemination in cattle. 7. Reprod. Fert. 19, 491.

Bedford, J. M. \& HunTer, R. H. F. (1968) The influence of X-irradiation of rabbit spermatozoa on fertilization and early cleavage. 7. Reprod. Fert. 17, 49.

Bishop, M. W. H., Campbell, R. G., Hancock, J. L. \& Walton, A. (1954) Semen characteristics and fertility in the bull. F. agric. Sci., Camb. 44, 227.

Cox, C. P. \& Melrose, D. R. (1953) The calibration of a photo-electric absorptionmeter for the rapid estimation of counts of spermatozoa in bull semen. F. agric. Sci., Camb. 43, 375.

Dziuk, P. J. (1965) Double mating of rabbits to determine capacitation time. F. Reprod. Fert. 10, 389.

Dzruk, P. J. (1970) Estimation of optimum time for insemination of gilts and ewes by double mating at certain times relative to ovulation. 7. Reprod. Fert. 22, 277.

EDwards, R. G. (1955) Selective fertilization following the use of sperm mixtures in the mouse. Nature, Lond. 175, 215.

Hancock, J. L. (1957) The morphology of boar spermatozoa. $\mathcal{F l}$ R. microsc. Soc. 76, 84.

Macmillan, K. L. \& Watson, J. D. (1971) The effect on conception rate of mixing semen from first and second ejaculates. $\mathcal{N} . Z$. $\mathcal{F l}$ agric. Res. 14, 702.

Mazumder, N. K. \& Spooner, R. L. (1970) Studies on bovine serum amylase; evidence for two loci. Anim. blood Grps biochem. Genet. 1, 145.

Mrleze, O. G., Roche, J. F. \& Dziuk, P. J. (1969) Estimation of the optimum interval between insemination and ovulation in the rabbit by double insemination. F. Reprod. Fert. 19, 545.

O'Reilly, P. J., Graves, G. N. \& DzuiK, P. J. (1972) Heterospermic insemination of rabbit semen as a means of evaluating techniques of semen handling. 7. Reprod. Fert. 29, 49.

Roche, J. F., Dziuk, P. J. \& LodGE, J. R. (1968) Competition between fresh and aged spermatozoa in fertilizing rabbit eggs. F. Reprod. Fert. 16, 155.

Spooner, R. L. \& Baxter, G. (1969) Abnormal expression of normal transferrin alleles in cattle. Biochem. Genet. 2, 371. 